\title{
Analytical Description of the Criterion \\ for the Columnar-To-Equiaxed Transition During Laser Beam Welding of Aluminum Alloys
}

\author{
CONSTANTIN BÖHM (D, CHRISTIAN HAGENLOCHER, JONAS WAGNER, \\ THOMAS GRAF, and STEFAN WEIHE
}

\begin{abstract}
An equiaxed grain structure in a laser welded seam is beneficial. In current literature the material and process perspective are addressed separately. This paper combined the material and process perspective in one analytical expression in order to access a deeper understanding of the key parameters for an equiaxed solidification during laser beam welding. For this, the steady state model of Hunt for growth of equiaxed dendritic grains was combined with heat conduction calculations and nucleation theory. The derived analytical expression identified the minimum values of the welding parameters required for the growth of equiaxed dendritic grains and describe their interaction with the metallurgically given nucleation density. The theoretically derived analytical description agrees well with experimental results obtained with two different batches of EN AW-6016 over a wide-range of laser welding parameters. The analytical description summarizes the effects of nucleation processes, local solidification conditions and the influence of process parameters on the growth of equiaxed dendritic grains. Furthermore, the equation identifies the key alloy properties, which influence the required process parameter for an equiaxed solidification. For the first time, the full range of phenomena, including metallurgical and thermal effects, was merged in one analytical expression.
\end{abstract}

https://doi.org/10.1007/s11661-021-06238-0

(C) The Author(s) 2021

\section{INTRODUCTION}

THE grain structure in a laser welded seam affects its mechanical strength ${ }^{[1]}$ and its susceptibility to the formation of hot cracks. ${ }^{[2]}$ In particular an equiaxed dendritic grain structure provides significant advantages in terms of resistance against hot cracking and mechanical properties compared to a grain structure, which consists of elongated columnar dendritic grains. ${ }^{[1-3]}$ Figure 1(a) exemplarily depicts the horizontal section of a weld with solely columnar dendritic grains and Figure 1(b) the horizontal section of a weld with equiaxed dendritic grains in the center area of the weld. The samples were grinded and polished from the surface and etched with Barker's reagent ${ }^{[4]}$ before they were photographed under polarized light. A free of hot cracks weld seam is pivotal for current industrial applications, namely in manufacturing of car battery trays. Hot

CONSTANTIN BÖHM and STEFAN WEIHE are with the Material Testing Institute, University of Stuttgart, Pfaffenwaldring 32, 70569, Stuttgart, Germany. Contact E-mail: constantin.boehm@mpa.unistuttgart.de CHRISTIAN HAGENLOCHER, JONAS WAGNER, and THOMAS GRAF are with the Institut für Strahlwerkzeuge, University of Stuttgart, 70569, Stuttgart, Germany.

Manuscript submitted October 19, 2020; accepted March 7, 2021.

Article published online April 22, 2021 cracks must be avoided in the battery trays to ensure the required water and gas tightness. ${ }^{[5]}$

The formation of an equiaxed dendritic grain structure requires a sufficient formation of nuclei and melt undercooling at the beginning of the solidification. Over several decades, the material influence, namely growth restricting solute and potent nuclei, on grain refinement and equiaxed solidification was researched extensively in casting. ${ }^{[6-9]}$ Lately research focused on combining models, ${ }^{[8]}$ experimentally elucidating nucleation mechanisms ${ }^{[10,11]}$ and studying new approaches to more efficient grain refinement. ${ }^{[12]}$

In welding processes previous research addressed the metallurgical influence on the growth of equiaxed dendritic grains during gas tungsten arc welding of aluminum $^{[1]}$ and laser deposition welding of nickel alloys ${ }^{[1,13,14]}$ at welding velocities $v<6 \mathrm{~m} \mathrm{~min}^{-1}$. In particular the welding research focused on how equiaxed solidification can be favored by adding Al-Ti-B master alloys. ${ }^{[1,15]}$ However, the theoretical analysis of welding processes is sparse. Moreover, there is a growing interest in the comparable research field of laser fusion-based additive manufacturing on understanding the influences on equiaxed solidification. ${ }^{[16,17]}$ 
The laser welding parameters have to be adjusted in order to achieve nucleation in the center of the weld ${ }^{[15,19]}$ Different process parameters lead to a different weld grain structure. Prior work found that the incident laser power per unit depth and the welding velocity influence the growth of equiaxed dendritic grains in the center area of the weld seam. ${ }^{[20]}$ This model is based on a simple analytically calculated threshold value for the power per unit depth, which is derived from a special solution of the heat conduction equation to calculate the ratio between the temperature gradient $G$ and the solidification rate $R$. The solidifying grain structure was found to be equiaxed dendritic if the incident power per unit depth of the welded seam exceeded the predicted threshold value. The solidifying grain structure at the centerline of the weld was found to be columnar dendritic if the power per unit depth was lower than the threshold value.

However, the analytically calculated threshold value solely considers the influence of the welding parameters on the temperature gradient $G$ and the solidification rate $R$ during solidification and neglects the influence of the welding parameters on essential metallurgical phenomena such as melt undercooling and nucleation. The accepted nucleation theory ${ }^{[21]}$ suggests, that nucleation is strongly influenced by metallurgical effects such as solute diffusion and the undercooling processes. Schempp et al. investigated the influence of the metallurgical phenomena ${ }^{[22]}$ without considering the influence of the process parameters on the temperature field.

The present paper follows an analytical approach, which takes into account the key influence factors on both the material and process perspective. This enables the optimization of material and process in order to control these metallurgical phenomena by the laser welding process without any addition of Al-Ti-B based filler materials. A wide range of laser welding parameters is used to investigate their influence on the criterion for columnar-to-equiaxed transition.

\section{METHODS}

\section{A. Experimental Set-Up}

The aluminum alloy AlSi1.2-Mg0.4 specified as EN AW-6016 by the European standard DIN EN 573-3 $3^{[23]}$ - also known as AA6016 - was welded in order to investigate the influence of the process parameters and the alloy properties on the resulting grain structure. In total, two batches of EN AW-6016 were welded. The alloys are hereinafter referred to as 6016-A and 6016-B. The experimental results of 6016-B were previously published. ${ }^{[20]}$

The 6016-A alloy was welded with two disk lasers, the TruDisk 8001 and the TruDisk 16002 from TRUMPF. Both operate at a wavelength of $\lambda=1.03 \mu \mathrm{m}$. The beam of the TruDisk 8001 laser was delivered through a fiber with a core diameter of $100 \mu \mathrm{m}$ and a nominal numerical aperture of 0.1. A fiber with a core diameter of $200 \mu \mathrm{m}$ (nominal numerical aperture of 0.1 ) was used with the TruDisk 16002 . The resulting $M^{2}$ were 15.3 (TruDisk
8001 ) and 30.5 (TruDisk 16002). The magnification of the focusing optics was $2.8: 1$ for both cases resulting in focal diameters of $d_{f}=280 \mu \mathrm{m}$ and $d_{f}=560 \mu \mathrm{m}$ and in Rayleigh lengths of 3.92 and $7.84 \mathrm{~mm}$, respectively. The beam was focused on the surface of the work piece in both set-ups. The samples were moved with a linear axis at constant welding velocities while the focusing optics were stationary. The 6016-A samples were $45 \mathrm{~mm}$ wide, $105 \mathrm{~mm}$ long and $2.0 \mathrm{~mm}$ thick. The length of the seams was $80 \mathrm{~mm}$ in order to carry out the investigations in a thermal steady-state condition. The processing optics were inclined opposite to the welding direction by $15^{\circ}$.

The laser power $P$ was adjusted for each welding velocity $v$ to achieve full penetration welding. In the case of full penetration welding the weld pool depth is equal to the sheet thickness $t_{\text {depth }} \hat{=} t_{\text {sheet }}$. At $v=1 \mathrm{~m} \mathrm{~min}^{-1}$ this results in a power per unit depth $P_{\text {depth }}=P \cdot t_{\text {depth }}^{-1}$, which is almost equal to the analytically calculated threshold value $P_{\text {depth }}=677 \mathrm{Wmin}^{-1}$ derived by a previous study ${ }^{[20]}$ that separates the formation of columnar and of equiaxed dendritic grain structures. To analyze this transition of the solidification behavior in more detail, trials with a variation of the laser power in several steps close to the threshold value were performed with $v=1 \mathrm{~m} \mathrm{~min}^{-1}$. Further experiments were performed with different welding velocities between $v=3-12 \mathrm{~m} \mathrm{~min}^{-1}$ and adjusted powers in order to achieve full penetration with constant focus diameter. The welding velocity was varied to investigate its influence on the solidified grain structure. The chosen values of the welding velocity $v$, the focus diameter $d_{f}$ and the power $P$ for the welding experiments of 6016-A are listed in Table I.

\section{B. Metallographic Analysis}

The welded samples were grinded and polished mechanically. All the depicted cross sections are surface parallel. The polished surfaces were then anodically
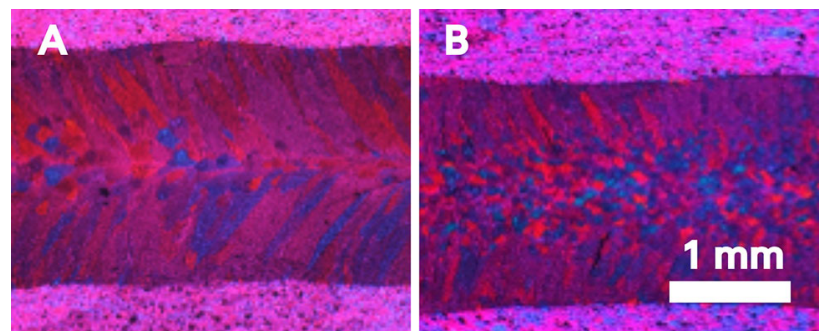

Fig. 1-Optical micrographs viewed under polarised light show different dendritic grain structure in the weld seam of EN AW-6016 for different process parameters. Etching with Barker's reagent ${ }^{[4]}$ of surface-parallel cross section of weld seam under polarized light revealing the grain structure. (a) Predominantly columnar dendritic grain structure obtained with full penetration laser beam welding with a focus diameter of $100 \mu \mathrm{m}$, a welding velocity of $3 \mathrm{~m} \mathrm{~min}-1$ and a laser power of $1500 \mathrm{~W}$. (b) Equiaxed dendritic grain structure in weld center area obtained with full penetration laser beam welding with a focus diameter of $600 \mu \mathrm{m}$, a welding velocity of $6 \mathrm{~m}$ $\mathrm{min}^{-1}$ and a laser power of $4300 \mathrm{~W}$ (altered figure on page 24, reprinted with permission from Reference [18]). 
etched with Barker's reagent ${ }^{[4]}$ for a duration of 120 seconds at a voltage of $16 \mathrm{~V}$. The etched samples were analyzed by means of an optical microscope with polarized illumination to reveal the grain structure. The size of the equiaxed dendritic grains was determined with the line intercept method according to DIN EN ISO 643. ${ }^{[24]}$ The grain size was measured in the proximity to the weld centerline and only if an equiaxed dendritic grain structure was present. Figure 2 shows a surface-parallel cross section of the grain structure of a weld seam. The measurement of the grain size was repeated three times for each weld seam with a $2 \mathrm{~mm}$ long reference line. The diameter of the equiaxed dendritic grains were experimentally determined by

Table I. Process Parameter Values for Full Penetration Laser Welding Trials of 6016-A

\begin{tabular}{lcc}
\hline Welding & $\begin{array}{c}\text { Focus Diameter } \\
d_{\mathrm{f}}(\mu \mathrm{m})\end{array}$ & $\begin{array}{c}\text { Power } \\
P(\mathrm{~W})\end{array}$ \\
\hline 1 & 280 & 1100 \\
& & 1200 \\
& & 1500 \\
3 & & 1600 \\
6 & 560 & 2500 \\
9 & 560 & 3100 \\
12 & 560 & 4200 \\
\hline
\end{tabular}

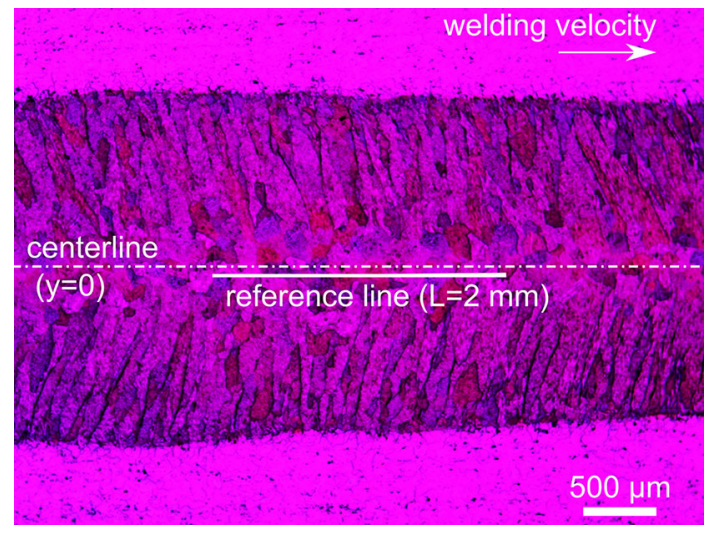

Fig. 2-Optical micrograph etched with Barker's reagent ${ }^{[4]}$ of surface-parallel cross section under polarized light revealing the grain structure. The line intercept method was used to determine the size of the equiaxed dendritic grains near the center of the welded seam $\left(6016-\mathrm{A} P_{\text {depth }}=1250 \mathrm{~W} \mathrm{~mm}{ }^{-1} ; v=3 \mathrm{~m} \mathrm{~min}^{-1} ; d_{\mathrm{f}}=560 \mu \mathrm{m}\right.$. dividing the length of a reference line by the number of grains which were intersected by the reference line. The arithmetic mean $d_{\text {mean }}$, minimum $d_{\text {min }}$ and maximum $d_{\max }$ of the size of the equiaxed dendritic grains were determined for all the samples.

\section{Calculation of the Thermophysical Properties}

The thermophysical properties of the used material, such as the heat capacity $c_{\mathrm{p}}$, density $\rho$ and liquidus temperature $T_{\text {liq }}$, were required to solve the heat conduction equation and calculate the temperature gradient at the location of the solidification. The values of these quantities were determined using the equilibrium calculator of Thermo-Calc $2020 \mathrm{a}^{[25]}$ with the aluminum data base TCAL v5.1. Table II lists the composition range for the EN AW-6016 standard. ${ }^{[23]}$

The composition range leads to different possible thermophysical properties. Table III summarizes all possible thermophysical properties used in this study. The minimum and maximum values calculated by Thermo-Calc 2020a are highlighted with "TC" in the source column.

The possible thermophysical properties (Table III) influence the temperature field during the welding process. Therefore, the possible thermophysical properties influence the solidification. In the following sections all equations were solved for the minimum and maximum possible values of the thermophysical properties in order to consider the possible variance within the standard EN AW-6016.

\section{THEORY}

\section{A. Criterion for the Columnar-To-Equiaxed Transition}

The model used in this study for the columnar-to-equiaxed transition is described by Hunt. ${ }^{[21]}$ This model considers the directional dendritic growth of the grains into an undercooled melt. The model for the columnar-to-equiaxed transition was already applied successfully for laser deposition welding of nickel alloys $^{[14]}$ and gas tungsten arc welding (GTAW) of aluminum alloys. ${ }^{[1]}$ The criterion for the columnar-to-equiaxed transition

$$
\frac{G^{3}}{R^{1.5}} \leq \frac{4 \pi}{81 \Phi_{E}} A_{i}^{3} N_{\text {active }}
$$

takes into account the local solidification conditions, namely temperature gradient $G$ and solidification rate $R$, where $\Phi_{\mathrm{E}}$ is the extended volume fraction of the

Table II. Composition Range of the EN AW-6016 Standard Specified in DIN EN 573-3 ${ }^{[23]}$

\begin{tabular}{lcccccc}
\hline & $\mathrm{Si}$ (wt. pct.) & Fe (wt. pct.) & $\mathrm{Cu}$ (wt. pct.) & Mn (wt. pct.) & Mg (wt. pct.) & Al (wt. pct.) \\
\hline Composition Range & 1.0 to 1.5 & 0.5 & 0.2 & 0.2 & 0.25 to 0.60 & balance \\
Composition Minimum & 1.0 & 0 & 0 & 0 & 0.25 & balance \\
Composition Maximum & 1.5 & 0.5 & 0.2 & 0.2 & 0.6 & balance \\
\hline
\end{tabular}


equiaxed dendritic grains to the columnar dendritic grains, $A_{i}$ the alloy parameter defined by Hunt, and $N_{\text {active }}$ the active nucleation density. ${ }^{[21]}$ The growth of equiaxed dendritic grains is driven by latent heat. ${ }^{[28]}$ However, as shown by Hunt, ${ }^{[21]}$ the limit of the criterion for the columnar-to-equiaxed transition (CET) can be analytically described only with the temperature gradient and the solidification rate neglecting the latent heat.

In laser beam welding of commercial aluminum alloys nucleation for equiaxed dendritic growth is driven only by heterogeneous substrate particles, namely $\mathrm{TiB}_{2}$, as shown by Geng et al. ${ }^{[15]}$ Based on the results of Geng et al. the analytical description presented in this work considers only heterogeneous nucleation. Hunt ${ }^{[21]}$ assumed the grain structure to be fully equiaxed for an extended volume fraction of $\Phi_{\mathrm{E}} \geq 0.66$. A statistical consideration of the competitive growth between columnar and equiaxed dendritic grains leads to this assumption. Therefore, a full equiaxed dendritic grain structure occurs when the ratio of the local solidification parameters $G_{\text {req }}^{3} / R_{\text {req }}^{1.5}$ is equal or smaller than the right hand side of Eq. [1]. From now on, the subscript "req" is added to the local solidification parameters corresponding to the limit case for equiaxed dendritic grain growth where the left hand side equals the right hand side of Eq. [1]. In this case and assuming $\Phi_{\mathrm{E}}=0.66$ for a fully equiaxed dendritic grain structure one finds

$$
\frac{G_{\text {req }}^{3}}{R_{\text {req }}^{1.5}} \approx 0.235 \cdot N_{\text {active }} A_{i}^{3}
$$

\section{B. Calculating the Alloy Parameters}

The criterion for the columnar-to-equiaxed transition in Eq. [2] requires the knowledge about additional material parameters: the active nucleation density $N_{\text {active }}$ and the alloy specific parameter $A_{i}$. The active nucleation density of one welded sample

$$
N_{\text {active }}=\left(\frac{1}{d}\right)^{3}
$$

results from the size $d$ of the equiaxed dendritic grains under the assumption that each equiaxed dendritic grain originates from one nucleation particle. It is important to note that the active nucleation density is influenced by the amount of $\mathrm{TiB}_{2}$ particles available, as shown by the addition of Al-Ti-B filler material during welding. ${ }^{[1]}$ Therefore, the active nucleation density can vary for different batches of an alloy within a standard. This is considered in the experimental part of this work by using an empirical model for the active nucleation density.

For binary alloys, ${ }^{[29]}$ the alloy specific parameter

$$
A_{i}=2\left[\frac{-2 m_{\mathrm{liq}}\left(1-k_{0}\right) c_{0} \Gamma}{D_{l}}\right]^{0.5}
$$

results from the slope of the equilibrium liquidus line $m_{\text {liq }}$, the equilibrium partition coefficient $k_{0}$, the alloy concentration $c_{0}$, the Gibbs-Thomson coefficient $\Gamma$, and the liquid diffusion rate $D_{l}$. As this study focusses on the influence of process parameters on the nucleation process and for the sake of simplification a pseudo-binary approach ${ }^{[30]}$ was used to approximate the alloy specific parameter $A_{i}$ for the multi-component EN AW-6016 alloy. In general the growth restriction factor is used to describe the effect of the alloy composition on the melt undercooling. For a more detailed model also other approaches can be applied. ${ }^{[12,31]}$ The multi-component alloy is reduced to a binary alloy Al-X with a summed alloy concentration

$$
c_{0, X}=\sum c_{i}
$$

The pseudo-binary alloy concentration $c_{0, X}$ was calculated with the minimum and maximum composition in Table II. All elements listed in Table II were considered for the following calculations. It is assumed that the reduced pseudo-binary alloy $\mathrm{Al}-\mathrm{X}$ has an equilibrium liquidus and solidus temperature equal to the one of the multi-component alloy. This approach is limited to alloys that form predominantly $\alpha$-Al as their primary phase during solidification, such as EN AW-6016. Kozlov and Schmid-Fetzer ${ }^{[31]}$ illustrated this for the calculation of the growth restriction factor for different compositions of a Al-Si-Mg-Cu alloy. The liquidus slope $m_{\text {liq. } X}$, the solidus slope $m_{\mathrm{sol}, X}$ and the partition coefficient $k_{0, X}$ are calculated similar to a linearized binary phase diagram. The equilibrium liquidus temperature $T_{\text {liq }}$ and equilibrium solidus temperature $T_{\text {sol }}$ were calculated with Thermo-Calc 2020a for the minimum and maximum composition as shown in Table II. The results of the equilibrium liquidus temperature $T_{\text {liq }}$ and equilibrium solidus temperature $T_{\text {sol }}$ are listed in Table III. The slope of the liquidus line of the pseudo-binary alloy

$$
m_{\mathrm{liq}, X}=\frac{T_{\mathrm{liq}}-T_{\mathrm{melt}}}{c_{0, X}}
$$

is the temperature difference between the equilibrium liquidus temperature $T_{\text {liq }}$ and the melting point of pure aluminum $T_{\text {melt }}$ divided by the alloy concentration of the pseudo-binary $c_{0, X}$, resulting from Eq. [5]. The slope of the solidus line of the pseudo-binary alloy

$$
m_{\mathrm{sol}, X}=\frac{T_{\mathrm{sol}}-T_{\mathrm{melt}}}{c_{0, X}}
$$

is calculated in a similar fashion. The equilibrium partition coefficient

$$
k_{0, X}=\frac{m_{\mathrm{liq}, X}}{m_{\mathrm{sol}, X}}
$$

of the pseudo-binary alloy is calculated from the ratio of the previous two slopes calculated by Eqs. [6] and [7]. The liquid diffusion coefficient

$$
D_{l, X}=\frac{1}{c_{0, X}} \sum c_{i} D_{l, i}\left(T_{\mathrm{liq}}\right)
$$


Table III. List of All Used Thermophysical Properties in This Work Within Minimum and Maximum Composition of EN AW-6016 Standard

\begin{tabular}{llccc}
\hline & Abbr. (Unit) & Min. Composition & Max. Composition & Source \\
\hline Liquidus Temperature & $T_{\text {liq }}(K)$ & 926 & 919 & TC \\
Ambient Temperature & $T_{\text {amb }}(K)$ & 300 & & - \\
Melting Point & $T_{\text {melt }}(K)$ & 933 & 836 & TC \\
Solidus Temperature & $T_{\text {sol }}(K)$ & 870 & 2391.2 & TC \\
Liquid Density $\left(T=T_{\text {liq }}\right)$ & $\rho_{l}\left(\mathrm{kgm}^{-3}\right)$ & 2377.7 & 2706.9 & TC \\
Solid Density $(T=300 K)$ & $\rho_{s}\left(\mathrm{kgm}^{-3}\right)$ & 2691.5 & 896 & TC \\
Heat Capacity $(T=300 K)$ & $c_{p}\left(\mathrm{Jkg}^{-1} \mathrm{~K}^{-1}\right)$ & 900 & & 26 \\
Interfacial Energy of Pure Aluminum & $\gamma_{s l}\left(\mathrm{Nm}^{-1}\right)$ & 0.9093 & 390 & TC \\
Enthalpy of Fusion & $H_{f}\left(\mathrm{kJkg}^{-1}\right)$ & 389 & 185.25 & 27 \\
Heat Conductivity & $\lambda_{t h}\left(\mathrm{Wm}^{-1} \mathrm{~K}^{-1}\right)$ & 204.25 & & \\
\hline
\end{tabular}

Table IV. Diffusion Coefficient in Liquid Aluminum Evaluated at $T_{\text {liq }}$ Original Data From Table IV ${ }^{[32]}$

\begin{tabular}{lcccccc}
\hline & Abbr. (Unit) & Al-Si & Al-Fe & Al-Cu & Al-Mn & Al-Mg \\
\hline Diffusion Coefficient & $D_{l, i}\left(10^{-9} m^{2} s^{-1}\right)$ & 2.802 & 2.568 & 4.804 & 9.703 & 3.548 \\
\hline
\end{tabular}

of the pseudo-binary alloy is calculated as a weighted mean over all alloying elements listed in Table II. The liquid diffusion coefficient in aluminum is gathered from Du et $a l^{[32]}$ and the values which were evaluated at liquidus temperature are listed in Table IV.

The Gibbs-Thomson coefficient

$$
\Gamma=\frac{\gamma_{s l}}{\Delta S_{f} \rho_{l}}
$$

of the pseudo-binary alloy describes the magnitude of the curvature effect during solidification of dendrites or small nucleation particles. ${ }^{[26]}$ The Gibbs-Thomson coefficient is defined as the interfacial energy $\gamma_{\mathrm{sl}}$ divided by the product of the entropy of fusion $\Delta S_{\mathrm{f}}=H_{\mathrm{f}} / T_{\text {melt }}$ and the liquid density of the alloy $\rho_{l}$ at the liquidus temperature.

Equation [10] is solved for the solid liquid interfacial energy $\gamma_{\mathrm{sl}}$ of pure aluminum, the melting point $T_{\text {melt }}$ of pure aluminum and the entropy of fusion $\Delta S_{f}$ and liquid density at liquidus temperature $\rho_{l}\left(T_{\text {liq }}\right)$ of the minimum and maximum composition from Table II of the EN AW-6016 alloy. The values used for Eq. [10] were calculated by Thermo-Calc 2020a TCAL v5.1 listed in Table III.

The resulting alloy parameter for alloys within the EN AW-6016 standard are calculated by Eq. [4] with the results of Eqs. [5], [6], [8], [9] and [10]. As listed in Table $\mathrm{V}$, the resulting alloy parameter ranges between $A_{i}=3.29-4.46 \mathrm{Ks}^{0.5} / \mathrm{mm}^{0.5}$. The results are in a similar range like the estimated value of $2 \mathrm{Ks}^{0.5} / \mathrm{mm}^{0.5}$ for a binary $\mathrm{AlCu} 2$ alloy ${ }^{[28]}$ and the empirically determined values between $1.2-1.7 \mathrm{Ks}^{0.5} / \mathrm{mm}^{0.5}$ for weld results of EN AW-1050 and EN AW-6082 in literature. $^{[1]}$

\section{Model for Active Nucleation Density}

The active nucleation density $N_{\text {active }}$ is a key alloy parameter according to Eq. [2] which is required to describe the growth of equiaxed dendritic grains. The heterogeneous nucleation particles have a specific size distribution as it is known from casting. ${ }^{[9]}$ The size or diameter of a particle determines at which melt undercooling it becomes active and promotes the growth of equiaxed dendritic grains. The free growth model describes this behavior. ${ }^{[26,28]} \mathrm{A}$ particle becomes active if the critical diameter

$$
d_{\text {crit }} \geq \frac{4 \gamma_{\mathrm{sl}}}{\Delta S_{\mathrm{f}} \Delta T_{\mathrm{c}}}
$$

is greater than the solid-liquid surface tension $\gamma_{s l}$ divided by the product of the degree of undercooling $\Delta T_{\mathrm{c}}$ and the entropy of fusion $\Delta S_{f}{ }^{[28]}$

For an aluminum melt Fraś et al. ${ }^{[33]}$ showed that the size distribution of heterogeneous nucleation particles can be described by a normal distribution. They calculated the active nucleation density

$$
N_{\text {active }}=\int_{d_{\text {crit }}}^{\infty} \frac{N_{\text {total }}}{d_{\mathrm{a}}} \exp \left(-\frac{d}{d_{\mathrm{a}}}\right) d \tilde{d}
$$

as the integral with the interval $\left[d_{\text {crit }}, \infty\right]$ including all particles greater than the critical diameter $d_{\text {crit }}$ and with a mean nucleation particle diameter of $d_{\mathrm{a}}$. Integrating Eq. [12] by the diameter $d$ for the interval $\left[d_{\text {crit }}, \infty\right]$ leads to

$$
N_{\text {active }}=N_{\text {total }} \exp \left(-\frac{d_{\text {crit }}}{d_{\mathrm{a}}}\right)
$$


Inserting Eq. [11] into Eq. [13] leads to the active nucleation density

$$
N_{\text {active }}=N_{\text {total }} \exp \left(-\frac{4 \gamma_{\mathrm{sl}}}{\Delta S_{\mathrm{f}} \Delta T_{\mathrm{c}} d_{\mathrm{a}}}\right)
$$

as an exponential function dependent on the total nucleation density $N_{\text {total }}$ and an exponent $-4 \gamma_{\mathrm{sl}} /\left(\Delta S_{\mathrm{f}} d_{\mathrm{a}} \Delta T_{\mathrm{c}}\right)$. The active nucleation density is a key parameter for the criterion for columnar-to-equiaxed transition according to Eq. [2] and it increases with a higher amount of melt undercooling $\Delta T_{\mathrm{c}}$ until it reaches its limit of $N_{\text {total }}$. Equation [14] describes the model based on nucleation theory.

\section{Influence of Process Parameter on Melt Undercooling}

The alloy specific parameter $A_{i}$ is required to calculate the melt undercooling $\Delta T_{\mathrm{c}}$ at a maximum growth rate. ${ }^{[29]}$ The melt undercooling

$$
\Delta T_{\mathrm{c}}=\frac{G D_{1}}{R}+A_{i} R^{0.5},
$$

is the sum of a diffusion based factor proportional to $G / R$ and an alloy specific parameter based factor proportional to $R^{0.5}$.

For laser welding, the solidification rate

$$
R=v \cos \alpha,
$$

is proportional to the welding velocity vand the angle $\alpha$ between the welding direction and the normal of the weld pool boundary neglecting the influence of the dendritic growth direction. ${ }^{[34]}$ This study is focused on the grain structure in the center area of the weld because there the equiaxed dendritic grains grow first. ${ }^{[34]}$ The solidification rate in the centerline equals to

$$
R_{\mathrm{CL}}=v
$$

because the angle between the weld direction and the normal of the weld pool boundary in the centerline is $\alpha_{C L}=0^{\circ}{ }^{\left[{ }^{34]}\right.}$ Furthermore, the temperature gradient in the centerline $G_{C L}$ is low according to Kou. ${ }^{[34]}$ Therefore, the first summand $G D_{l} / R$ of Eq. [15] is negligibly small compared to the second term $A_{i} R^{0.5}$ for laser beam welding. With this, the melt undercooling $\Delta T_{c}$ in the centerline of laser beam welding yields

$$
\Delta T_{\mathrm{c}}=A_{i} R_{\mathrm{CL}}^{0.5}=A_{i} v^{0.5}
$$

Eq. [18] shows that the melt undercooling $\Delta T_{c}$ is influenced by the solidification rate $R$ and according to Eqs. [16] and [17] from the welding velocity. The dashed black curve in Figure 3 represents the melt undercooling as a function of the welding velocity and the respective solidification rate at the centerline calculated according to Eq. [18] with the average alloy parameter of EN AW-6016 from Table V. The enveloping green curves of the green area in Figure 3 represent the minimum and maximum melt undercooling $\Delta T_{c}$ calculated by Eq. [18] with the minimum and maximum alloy parameter values for EN AW-6016 from Table V. According to Eq. [18], the metallurgical parameter of melt undercooling $\Delta T_{c}$ can be directly controlled by the process parameter, namely the welding velocity $v$.

\section{E. Influence of Process Parameter on Solidification Parameter}

The process parameters affect the type of solidification as indicated by Eq. [2]. When laser welding aluminum the grain types are typically either columnar or equiaxed dendritic. ${ }^{[34]}$ The driving solidification parameters, which are affected by the process parameters, are the solidification rate $R$ and the temperature gradient $G$. Eq. [2] shows that the required ratio of the local solidification parameters is $\left(G^{3} / R^{1.5}\right)_{\text {req }}$. This ratio $\left(G^{3} / R^{1.5}\right)_{\text {req }}$ must exceed the value defined by the criterion to achieve equiaxed dendritic growth. The special solution of the two dimensional heat flux equation for a fast moving line source by Rosenthal ${ }^{[35]}$ is used to approximate the temperature gradient $G$ at the location of the centerline. The solidification rate at the centerline is $R_{C L}=v$ according to Eq. [17]. Following the previously published approach, ${ }^{[20]}$ the ratio of $G / R$ is expressed using the special solution of the heat conduction as

$$
\frac{G}{R}=2 \pi \frac{\left(T_{\mathrm{liq}}-T_{\mathrm{amb}}\right)^{3} \lambda_{\mathrm{th}} \rho_{\mathrm{s}} c_{\mathrm{p}}}{\eta_{\mathrm{abs}}^{2} P_{\text {depth }}^{2}}
$$

where $T_{a m b}$ is the ambient temperature of the workpiece, $\lambda_{\text {th }}$ is the heat conductivity, $\rho$ is the solid density at room temperature and $c_{p}$ is the heat capacity at room temperature, $P_{\text {depth }}=P \cdot t_{\text {depth }}^{-1}$ is the power per unit depth and $\eta_{a b s}$ is the absorptance. The power per unit depth is derived from the special solution of the two dimensional heat equation by Rosenthal. ${ }^{[35]}$ It describes the amount of power evenly distributed over the depth of the line source. This study focusses on the case of full penetration laser welding. In this case the depth of the weld pool is equal to the thickness $t_{\text {sheet }}$ of the welded aluminum sheet. The absorptance $\eta_{a b s} \approx 70_{-10}^{+10} p c t$ was calculated according to Gouffe ${ }^{[36]}$ for a cylindrically shaped vapor capillary with an aspect ratio of $s / d_{f}=3.6$ (according to the experimental set-up in Table I) in liquid aluminum with an absorptivity ${ }^{[37]}$ of 12 pct. The variation in the absorptance of \pm 10 pct is an estimation addressing possible uncertainties.

\section{CRITERION FOR LASER BEAM WELDING}

A. Influence of Process Parameter on Active Nucleation Density

Inserting Eq. [18] into Eq. [14] leads to the active nucleation density 
Table V. Results of the Alloy Specific Parameter of EN AW-6016 Calculated by the Pseudo-Binary Approach

\begin{tabular}{lccc}
\hline & Abbr. (Unit) & Composition Minimum & Composition Maximum \\
\hline Alloy Specific Parameter & $A_{i}\left(\mathrm{Ks}^{0.5} / \mathrm{mm}^{0.5}\right)$ & 3.29 & 4.46 \\
\hline
\end{tabular}

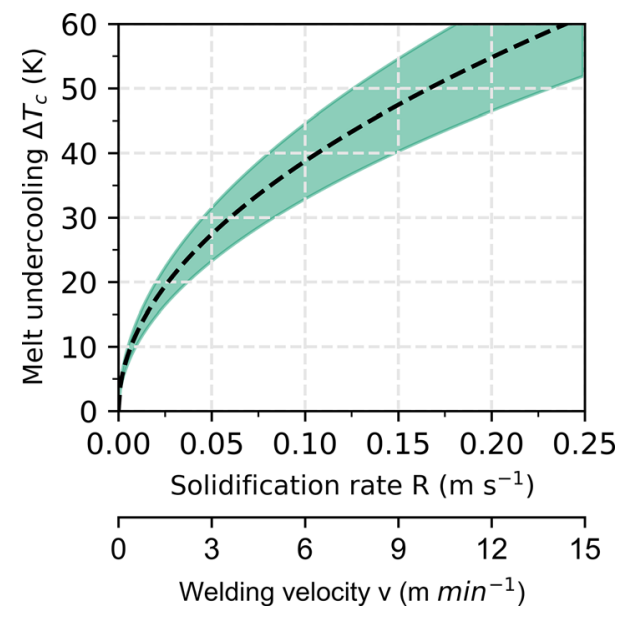

Fig. 3-Melt undercooling at the centerline as a function of the welding velocity calculated by Eq. [18].

$$
N_{\text {active }}=N_{\text {total }} \exp \left(-\frac{4 \gamma_{\mathrm{sl}}}{\Delta S_{\mathrm{f}} d_{\mathrm{a}} A_{i} v^{0.5}}\right)
$$

at the centerline of the weld as a function of the welding velocity $v$. The active nucleation density is a key alloy parameter to describe the criterion for columnar-to-equiaxed transition according to Eq. [2]. Increasing the welding velocity $v$ increases the active nucleation density $N_{\text {active }}$ according to Eq. [20] and promotes the growth of equiaxed dendritic grains according to Eq. [2]. Equation [20] combines the microscopic metallurgical phenomena of nucleation with the process parameter $v$. Since the active nucleation density for a specific welding velocity $v$ in an aluminum alloy is currently not known, a best fit of Eq. [20] is performed.

The data in Figure 4 present the influence of the welding velocity and the corresponding solidification rate at the centerline on the active nucleation density $N_{\text {active }}$ calculated by the empirically determined mean equiaxed dendritic grain size in the experiments according to Eq. [3]. The weld experiments using 6016-A are compared to the already published results obtained with 6016-B. ${ }^{[20]}$ The mean equiaxed dendritic grain size was determined by the line intercept method. No active nucleation density $N_{\text {active }}$ was determined for the welding velocities lower than $v<1 \mathrm{~m} \mathrm{~min}^{-1}$ for 6016 -B because no equiaxed dendritic grains were observed. The rectangular data points (purple) represent the results obtained with 6016-A and the error bars correspond to the minimum and maximum values of the experimentally determined active nucleation density $N_{\text {active }}$. At least three weld experiments were evaluated for each

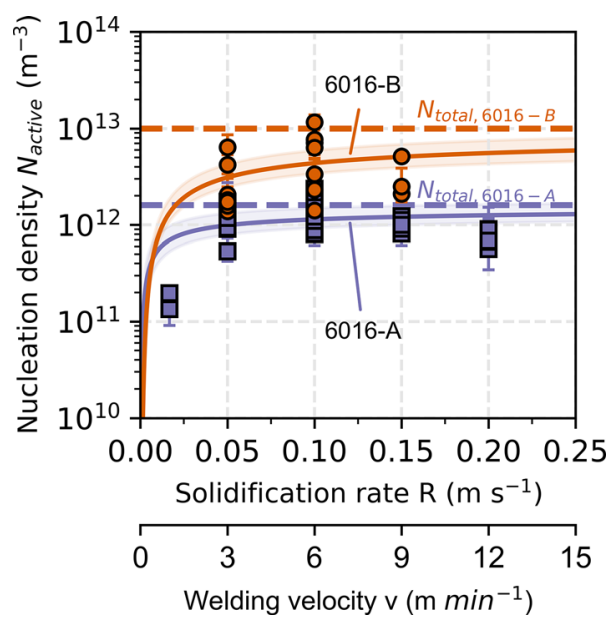

Fig. 4-Influence of the welding velocity $v$ and the respective solidification rate on the experimentally determined active nucleation density Nactive for 6016-A (rectangular purple) and 6016-B (circular orange). Solid curves represent a best fit of Eq. [20] for 6016-A (purple) and 6016-B (orange). Dashed lines represent limit of the nucleation density Ntotal for 6016-A (purple) and 6016-B (orange). (For interpretation of the references to color in this figure, the reader is referred to the online version of this article) (Color figure online).

Table VI. Results of the Best Fit of Eq. [20] for Both Alloys

\begin{tabular}{lll}
\hline & $N_{\text {total }}\left(\mathrm{m}^{-3}\right)$ & $b\left(\mathrm{~ms}^{-1}\right)$ \\
\hline $6016-\mathrm{A}$ & $1.6_{-0.2}^{+0.4} \cdot 10^{12}$ & $0.11_{-0.02}^{+0.01}$ \\
$6016-\mathrm{B}$ & $10.0_{-2.5}^{+3.2} \cdot 10^{12}$ & $0.26_{-0.01}^{+0.01}$ \\
\hline
\end{tabular}

velocity and each aluminum batch. The circular data points (orange) represent the previously published results obtained for $6016-\mathrm{B} .^{[20]}$

A best fit of Eq. [20] with the fit parameter $b=$ $4 \gamma_{s l} / \Delta S_{f} d_{a} A_{i}$ is performed individually for 6016-A and 6016-B. The results of the best fits of Eq. [20] are listed in Table VI.

The solid purple curve in Figure 4 represents the best fit of Eq. [20] for the experimental results of welding 6016-A. Additionally, the enveloping curves of the purple area represent the fit of Eq. [20] to the minimum and maximum values of the experimental results. The solid orange curve is the best fit of Eq. [20] to the results obtained for 6016-B with the filled orange area highlighting the minimum and maximum fit values. The purple dashed line in Figure 4 represents the fFfitted value of the nucleation density limit $N_{\text {total, } 6016-A}$ for 6016-A according to Eq. [20]. The orange dashed line in Figure 4 represents the fitted value of the nucleation density limit $N_{\text {total } 6016-B}$ for 6016-B according to Eq. [20]. 
The experimentally determined active nucleation density $N_{\text {active }}$ for 6016-A and 6016-B is scattered because the data points of the active nucleation density $N_{\text {active }}$ are sensitive to the measured grain size according to Eq. [3]. The experimentally determined active nucleation density $N_{\text {active }}$ in 6016-A increases by an order of magnitude between the welding velocities of $v=1 \mathrm{~m} \mathrm{~min}^{-1}$ and $v=3 \mathrm{~m} \mathrm{~min}^{-1}$. The active nucleation density $N_{\text {active }}$ in 6016-A and 6016-B quickly approaches the limit of $N_{\text {total }}$ due to the high melt undercooling caused by the high welding velocities $v>1 \mathrm{~m} \mathrm{~min}^{-1}$ of laser welding. This suggests that in particular for small welding velocities $v<1 \mathrm{~m} \mathrm{~min}^{-1}$ the influence of the welding velocity $v$ on the active nucleation density $N_{\text {active }}$ should be considered. As listed in Table IV the total nucleation density $N_{\text {total }}$ of 6016-A and 6016-B differs by an order of magnitude. This suggests an influence of the alloy batch on the distribution of heterogeneous nucleation particles. Furthermore, the approximated total nucleation densities for both alloy batches range from $10^{12} \mathrm{~m}^{-3}$ to $10^{13} \mathrm{~m}^{-3}$. In comparison to the range of the values of the nucleation density of $10^{9} \mathrm{~m}^{-3}$ to $10^{12} \mathrm{~m}^{-3}$ from literature given for an unspecified alloy ${ }^{[26]}$ the experimental results are near the upper limit or even larger. In conclusion, the active nucleation density $N_{\text {active }}$ modelled by Eq. [20] explains the quick saturation of the nucleation density $N_{\text {active }}$ due to the high melt undercooling according to Eq. [18]. Moreover, in particular for low welding velocities $v \leq 1 \mathrm{~m} \mathrm{~min}^{-1}$ the influence of the welding velocity on the active nucleation density $N_{\text {active }}$ should be taken into account, whereas for high welding velocities the active nucleation density can be considered as constant. The comparison of the two curves and the experimental results show the deviation of the nucleation density between the two investigated batches of EN AW-6016.

\section{B. Influence of Process Parameters on the Criterion}

The previously published heat conduction approach $^{[20]}$ should be combined with Hunt's criterion $^{[21]}$ in order to combine the metallurgical and the process perspective for the growth of equiaxed dendritic grains. For this the criterion for columnar-to-equiaxed transition Eq. [2] is extended with $1 / R^{1.5}$, which leads to

$$
\left(\frac{G}{R}\right)_{\text {req }}^{3}=0.24 \cdot A_{i}^{3} N_{\text {req }} \frac{1}{R_{\text {req }}^{1.5}} \text {. }
$$

Inserting Eq. [19] in Eq. [21] and replacing $R$ by the welding velocity $v$, using $P_{a b s, \text { depth }}=\eta_{a b s} P_{\text {depth }}$ and solving the equation for the nucleation density yields

$$
N_{\text {req }, \text { active }}=9.48 \cdot 10^{4}\left(\frac{\left(T_{\text {liq }}-T_{\mathrm{amb}}\right)^{3} \lambda_{\mathrm{th}} \rho_{\mathrm{s}} c_{\mathrm{p}}}{A_{i}}\right)^{3}
$$

as a function of the process parameters welding velocity $v$ and absorbed laser power per unit depth $P_{a b s, d e p t h}$. The welding velocity directly influences the required active nucleation density $N_{\text {req,active }} \sim v^{1.5}$ according to Eq. [22]. An increase of the welding velocity at constant power per unit depth lowers the required active nucleation density. This effect is also found for gas tungsten arc welding of aluminum alloys ${ }^{[1]}$. Moreover, Eq. [22] analytically proves the main influence of the absorbed power per unit depth on the criterion for columnar-to-equiaxed transition $N_{\text {req,active }} \sim P_{a b s, \text { depth }}^{-6}$, which agrees with the experimental findings of the prior study. ${ }^{[20]}$

Figure 5(a) exemplarily depicts the horizontal section of a weld with solely columnar dendritic grains and Figure 5(b) the horizontal section of a weld with equiaxed dendritic grains in the center area of the weld. The samples were grinded and polished from the surface and etched with Barker's reagent ${ }^{[4]}$ before they were photographed under polarized light. According to Eq. [22] if the absorbed power per depth is low then the active nucleation density required for the formation of equiaxed dendritic grains is high. Figure 5 experimentally shows that for a low $P_{\text {abs,depth }} \approx 180 \mathrm{~W} \mathrm{~min}^{-1}$ combined with a slow welding velocity $v=0.25 \mathrm{~m} \mathrm{~min}^{-1}$ (Figure 5(a)) there is no equiaxed dendritic grain structure and for a higher $P_{a b s, \text { depth }} \approx 2100 \mathrm{~W} \min ^{-1}$ combined with a faster welding velocity $v=12 \mathrm{~m} \mathrm{~min}^{-1}$ (Figure 5(b)) there is an equiaxed dendritic grain structure. According to Table I the absorptance is estimated to $\eta_{a b s} \approx 70_{-10}^{+10} p c t$ given by the equations of Gouffé ${ }^{[36]}$ for liquid aluminum and an aspect ratio of $t_{\text {sheet }} / d_{f}=3.6$.

In Figure 6 the predicted type of grain structure by Eq. [22] is compared to the experimentally observed type of grain structure of the two alloy batches with different nucleation densities. The criterion for columnar-to-equiaxed transition in Eq. [22] is evaluated for the resulting minimum and maximum thermophysical properties, listed in Table III. Thus, all possible alloy compositions of the EN AW-6016 standard are considered. The resulting minimum and maximum values of the criterion are represented by the enveloping curves of the green areas in Figure 6. The green areas divide the plot into two parameter ranges. The weld experiments which are welded within the parameter range left of the green area contain only columnar dendritic grains; the weld experiments which are welded within the parameter
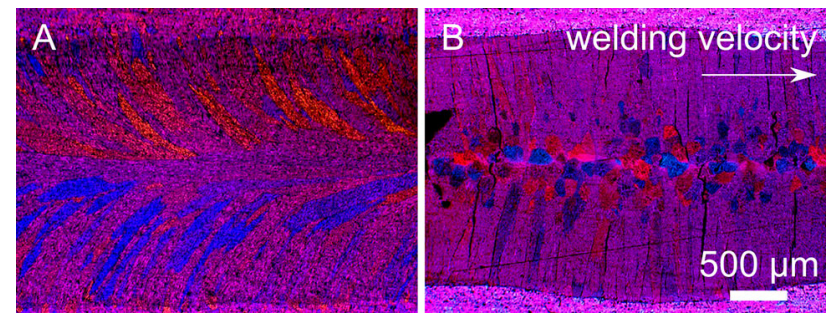

Fig. 5-Optical micrographs viewed under polarized light and etched with Barker's reagant reveal different dendritic grain structure. (a) Columnar dendritic grain structure obtained with a laser power of $620 \mathrm{~W}$, a welding velocity of $0.25 \mathrm{~m} \mathrm{~min}^{-1}$, a beam diameter of 50 $\mu \mathrm{m}$ and with a full penetration depth of $2.4 \mathrm{~mm}$. (b) Equiaxed dendritic grain structure in center area obtained with a laser power of $6000 \mathrm{~W}$, a welding velocity of $12 \mathrm{~m} \mathrm{~min}^{-1}$, a beam diameter of $560 \mu \mathrm{m}$ and with a full penetration depth of $2.0 \mathrm{~mm}$ 
(a) $1 \mathrm{~m} \mathrm{~min}^{-1}$

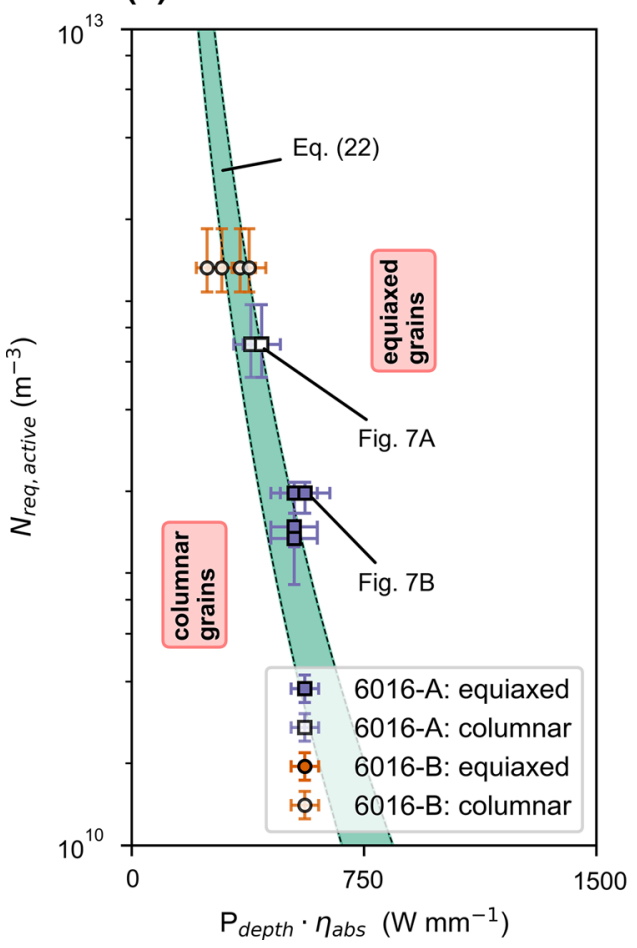

(b) $0.25 \mathrm{~m} \mathrm{~min}^{-1}$

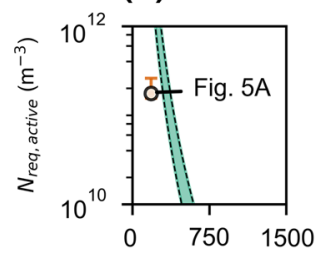

(d) $3 \mathrm{~m} \mathrm{~min}^{-1}$

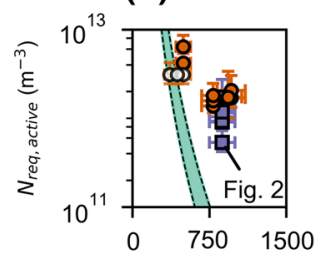

(f) $9 \mathrm{~m} \mathrm{~min}^{-1}$

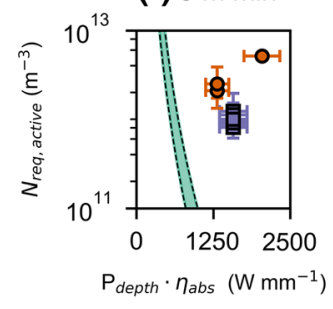

(c) $0.5 \mathrm{~m} \mathrm{~min}^{-1}$

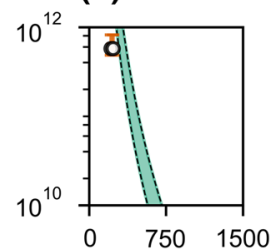

(e) $6 \mathrm{~m} \mathrm{~min}^{-1}$

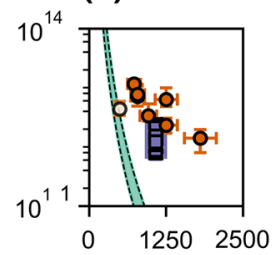

(g) $12 \mathrm{~m} \mathrm{~min}^{-1}$

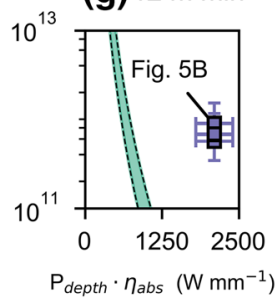

Fig. 6 - Comparison of the predicted type of grain structure by the analytically derived criterion for the columnar-to-equiaxed transition Eq. [22] and the experimental results for 6016-A and 6016-B. The enveloping curves of the green areas are calculated by the criterion for columnar-to-equiaxed transition using Eq. [22]. If data points are located right from the green areas then equiaxed dendritic grains are expected; if data points are located left from the green areas then columnar dendritic grains are expected. The data points for 6016-A (rectangular filled with purple) and 6016-B (circular filled with orange) are experimentally determined and labeled as "equiaxed". The active nucleation density of the data points for 6016-A (rectangular filled with white) and 6016-B (circular filled with white) were approximated by Eq. [20]. (For interpretation of the references to color in this figure, the reader is referred to the online version of this article.) Each of the investigated welding velocities are summarized in an extra figure. $(a)$ welding velocity $v=1 \mathrm{~m} \mathrm{~min}^{-1} ;(b) v=0.25 \mathrm{~m} \mathrm{~min}^{-1} ;(c) v=0.5 \mathrm{~m} \mathrm{~min}^{-1} ;(d) v=3 \mathrm{~m} \mathrm{~min}{ }^{-1} ;(e)$ $v=6 \mathrm{~m} \mathrm{~min} \min ^{-1} ;(f) v=9 \mathrm{~m} \mathrm{~min}^{-1} ;(g) v=12 \mathrm{~m} \mathrm{~min}^{-1}$ (Color figure online).

range right of the green area contain equiaxed dendritic grains. If the chosen weld parameters are located close to the green areas then an increase in uncertainty is expected.

Figure 6 depicts the experimentally determined active nucleation density for the conducted experiments that lead to an equiaxed dendritic grain structure and its influence of the absorbed power per unit depth $P_{a b s, d e p t h}$. Each subplot summarizes the results for a specific welding velocity. The data points for 6016-A (rectangular filled with purple) and 6016-B (circular filled with orange) represent the experimentally data of the active nucleation density $N_{\text {active }}$ and are labeled as "equiaxed" dendritic grains in Figure 6. The vertical error bars of the experimentally determined data points result from the minimum and maximum measured active nucleation density $N_{\text {active }}$. The horizontal error bars of the experimentally determined data points in Figure 6 result from the uncertainty of the estimated absorptance $\eta_{a b s} \approx$ $70_{-10}^{+10}$ pct. According to Table I the absorptance is estimated to $\eta_{a b s} \approx 70_{-10}^{+10} p c t$ given by the equations of Gouffe $^{[36]}$ for liquid aluminum and an aspect ratio of $t_{\text {sheet }} / d_{f}=3.6$.

The active nucleation density $N_{\text {active }}$ can be determined experimentally with Eq. [3] only when equiaxed dendritic grains are observed in the metallographic cross sections. For the weld experiments that did not lead to an equiaxed dendritic grain structure, the theoretical value of the active nucleation density (Figure 5(a)) were therefore approximated by Eq. [20]. The data points with white filling were approximated by Eq. [20] for 6016-A (rectangular filled with white) and 6016-B (circular filled with white) and are labeled as "columnar" dendritic grains in Figure 6. The vertical error bars of the data points with a calculated active nucleation density results from the minimum and maximum deviations of the best fit for each alloy batch listed in Table V. The horizontal error bars of the calculated data points in Figure 6 result from the uncertainty of the estimated absorptance $\eta_{a b s} \approx 70_{-10}^{+10}$ pct.

All the data points with an approximated nucleation density depicted with white filling in Figures 6(b) through (e) are located left or in close proximity of the enveloping curves of the green areas. The combination of material and process perspective given by Eqs. [20] and [22] explains why the growth of columnar dendritic grains occurs in the centerline for the weld that did not lead to the growth of equiaxed dendritic grains. The occurrence of the growth of columnar dendritic grains is well described although the active nucleation density is overestimated by the best fit of Eq. [20] for welding velocities 
$v \leq 1 \mathrm{~m} \mathrm{~min}^{-1}$. All of the data points with an observed equiaxed dendritic grain structure (depicted with orange or purple filling in Figure 6) are located right (Figures 6(d) through (g)) or within (Figure 6(a)) the enveloping curves of the green areas. Hence, the combination of the material and process perspective described by Eq. [22] reliably explains the observed occurrence of the growth of equiaxed dendritic grains. In conclusion, although two batches of EN AW-6016 with different nucleation densities were welded the proposed analytical expression of Eq. [22] agrees well with the experimental findings within the range of the possible thermophysical properties, as listed in Table III. The strong decrease of the active nucleation density with increasing $P_{\text {depth }} \cdot \eta_{a b s}$ shows clearly the major influence of the process parameters on the formation of an equiaxed dendritic zone compared to the small range of the green area, which represents deviation of the thermophysical properties within the EN AW-6016 standard. For the first time, the process parameter perspective was described analytically for equiaxed solidification in full penetration laser beam welding.

The experimental results at welding velocities $v \geq$ $9 \mathrm{~m} \mathrm{~min}^{-1}$ (Figures 6(f) through (g) highlight two beneficial effects for the growth of equiaxed dendritic grains. First, high welding velocities lead to a higher value of the melt undercooling according to Eq. [18] and subsequently to a higher active nucleation density according to Eq. [20]. Second, the powers per unit depth $P_{\text {depth }}$ must generally be higher to achieve full penetration welding and thus the experimentally determined values of the power per unit depth are found at the right of the enveloping curves of the green areas calculated by Eq. [22].

The analytical description of the criterion by Eq. [22] highlights that the required active nucleation density $N_{\text {active }}$ directly depends on the absorbed power per unit depth $P_{a b s, d e p t h}$ and the welding velocity $v$. Geng et al. ${ }^{[38]}$ experimentally analyzed the nucleation mechanisms for laser welding of aluminum and found that only heterogeneous substrate particles, such as Ti-B, induce the formation of equiaxed dendritic grains. Schempp and Rethmeier $^{[1]}$ investigated the influence of Al-Ti-B filler wire additions on gas tungsten arc welding of aluminum and found that increasing the nucleation density by adding Al-Ti-B filler wire at constant welding parameters leads to a decrease of the grain size as an effect of the growth of equiaxed dendritic grains. Eq. [22] gives the required absorbed power per unit depth $P_{\text {req,abs,depth }}$ for a given nucleation density. Subsequently, Eq. [22] could help to achieve the growth of equiaxed dendritic grains for a given nucleation density and thus increasing the mechanical performance of the alloy without any addition of Al-Ti-B based filler materials.

\section{Metallographic Analysis at the Threshold of the Criterion}

At a critical number of growing equiaxed dendritic grains the growth of columnar grains is blocked and the solidifying grain structure is considered to be fully equiaxed. The columnar dendritic grains overgrow the equiaxed dendritic in case that the critical number is not reached. ${ }^{[21]}$ Therefore, a transition behavior located within the enveloping curves of the green areas is expected.

The additional variation of the welding experiments with 6016-A at $v=1 \mathrm{~m} \mathrm{~min}^{-1}$ (purple data points filled with white in Figure 6(a) result in a power per unit depths $P_{\text {depth }}$ close to the critical value given by Eq. [22]. Figure 7(a) shows the grain structure of seam in 6016-A which was welded with $v=1 \mathrm{~m} \mathrm{~min}^{-1}$ and $P_{\text {depth }}=650 \mathrm{~W} \mathrm{~min}{ }^{-1}$. The grain structure seen in Figure 7(a) is columnar dendritic. Yellow arrows indicate the positions with a low number of equiaxed dendritic grains. Figure 7(b) shows the grain structure of a seam in 6016-A welded with $v=1 \mathrm{~m} \mathrm{~min}^{-1}$ and a higher power per unit depth $P_{\text {depth }}=800 \mathrm{~W} \mathrm{~min}^{-1}$. The grain structure seen in Figure $7(\mathrm{~b})$ is fully equiaxed dendritic. The transition behavior from the growth of columnar to equiaxed dendritic grains is consistent with the here presented analytical description in Eq. [22] and the findings of Hunt. ${ }^{[21]}$ According to Eq. [22] the absorbed depth specific energy $P_{\text {abs,depth }}$ must be increased in order to achieve an equiaxed dendritic grain structure for a given active nucleation density. The experiments presented in Figure 7 were conducted with a velocity of $1 \mathrm{~m} \mathrm{~min}^{-1}$. According to Eq. [20] the active nucleation density $N_{\text {active }}$ for both weld experiments in Figures 7(a) and (b) are equal. The experiments confirm this prediction. Hence, the discussed experimentally observed transition behavior validates the analytical description derived in this study.

\section{IMPLICATIONS FOR PROCESS AND ALLOY DESIGN}

Inserting the description of the active nucleation density function Eq. [20] into Eq. [22] and solving for the absorbed power per unit depth leads to the absorbed power per unit depth
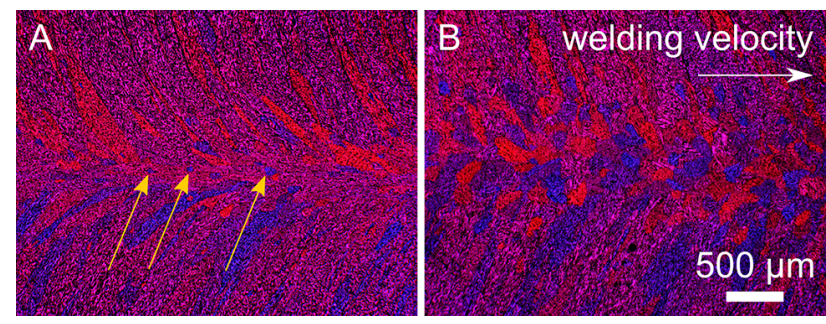

Fig. 7-Optical micrographs viewed under polarized light and etched with Barker's reagant show solidification behaviour of 6016-A close to the critical value as calculated by Eq. [22]. (a) Mainly columnar dendritic grain structure is observed. Yellow arrows highlight single equiaxed dendritic grains. $P=650 \mathrm{~W} \mathrm{~mm}^{-1}, v=1 \mathrm{~m} \mathrm{~min}^{-1}, \quad d_{\mathrm{f}}=$ $280 \mu \mathrm{m}$. (b) Equiaxed dendritic grain structure is observed in the centerline. $P_{\text {depth }}=800 \mathrm{~W} \mathrm{~mm}^{-1}, v=1 \mathrm{~m} \mathrm{~min}^{-1}, d_{\mathrm{f}}=280 \mu \mathrm{m}$. 


$$
\begin{aligned}
P_{\text {req,abs,depth }}= & 6.75\left(\frac{1}{N_{\text {total }}} \exp \left(\frac{4 \gamma_{\mathrm{sl}}}{\Delta S_{\mathrm{f}} d_{\mathrm{a}} A_{i} v^{0.5}}\right)\right)^{\frac{1}{6}} \\
& \times\left(\frac{\left(T_{\text {liq }}-T_{\mathrm{amb}}\right)^{3} \lambda_{\mathrm{th}} \rho_{\mathrm{s}} c_{\mathrm{p}}}{A_{i}}\right)^{\frac{1}{2}} v^{\frac{1}{4}}
\end{aligned}
$$

that is required to obtain an equiaxed dendritic growth as a function of the active nucleation density $N_{\text {active }}$, the welding velocity $v$ and the extended alloy parameter

$$
\xi=\frac{\left(T_{\mathrm{liq}}-T_{\mathrm{amb}}\right)^{3} \lambda_{\mathrm{th}} \rho_{\mathrm{s}} c_{\mathrm{p}}}{A_{i}}
$$

Equation [23] proves that increasing the active nucleation density $N_{\text {active }}$ lowers the required absorbed power per unit depth $P_{\text {req,abs,depth }}$. Moreover, Eq. [23] allows to design the process and calculate the required absorbed power per unit depth $P_{\text {req,abs,depth }}$ for a specific welding velocity $v$ and a given nucleation density. Applying Eq. [23] for 6016-A and 6016-B results in the values of the process parameters that are required for the nucleation and the subsequent growth of equiaxed dendritic grains. Figure 8 shows the absorbed power per unit depth $P_{\text {req,abs,depth }}$ required for the growth of equiaxed dendritic grains as a function of $v$ in the range of 1 to $12 \mathrm{~m} \mathrm{~min}^{-1}$ for $6016-\mathrm{A}$ and $6016-\mathrm{B}$. Only the range of welding velocities is considered in Figure 8 in which the growth of equiaxed dendritic grains was observed in the experiments. The enveloping curves of the purple area (6016-A) represent the minimum and maximum required power per unit depth as calculated using the minimum and maximum values of the alloy properties listed in Table III and with the mean values of the best fit of Eq. [20] given in Table V. The enveloping curves of the orange area (6016-B) represent the minimum and maximum required power per unit depth value calculated using the minimum and maximum alloy properties

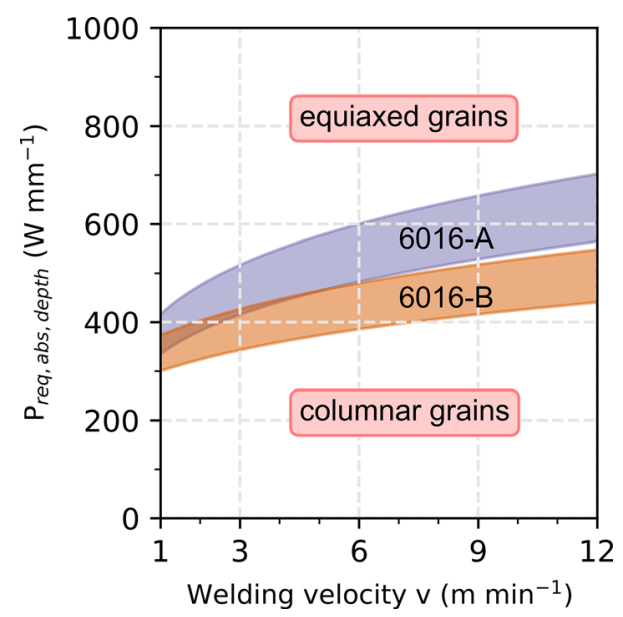

Fig. 8-Absorbed power per unit depth as a function of the welding velocity that is required for the growth of equiaxed dendritic grains for two batches of EN AW-6016. Calculated by Eq. [23] using the mean nucleation density values listed in Table VI and the minimum and maximum alloy properties listed in Table III. listed in Table III and with the mean values of the best fit of Eq. [20] given in Table IV.

The growth of equiaxed dendritic grains is expected when the absorbed power per unit depth exceeds the maximum theoretically calculated power per unit depth which is required for equiaxed grain growth $P_{\text {req,abs,depth }}$. The upper purple boundary in Figure 8 represents the maximum values of $P_{\text {req,abs,depth }}$ as a function of the welding velocity. These maximum values are proposed as an initial value to obtain equiaxed dendritic grain growth for other alloys specified within the EN AW-6016 standard.

Equation [2] highlights the active nucleation density $N_{\text {active }}$ and the alloy parameter $A_{i}$ as the main material parameters of the criterion for growth of equiaxed dendritic grains by Hunt. ${ }^{[21]}$ Equation [23] includes the special solution of the heat conduction equation as well as the nucleation theory. It is the specific relation for the growth of equiaxed dendritic grains for laser beam welding. This is why Eq. [23] reveals more material parameters than the active nucleation density $N_{\text {active }}$ and the alloy parameter $A_{i}$ as originally described by Hunt. ${ }^{[21]}$ Eqquation [23] presents a much more detailed view on the influence of the material on the equiaxed dendritic grain growth and Eq. [24] summarizes them as the here defined extended alloy parameter $\xi$ which can be used as an alloy design metric.

For the following statements it is assumed that the aim is to reduce the required absorbed power per unit depth $P_{\text {req,abs,depth. }}$ Then Eq. [24] implies that either $A_{i}$ could be increased which also increases the melt undercooling according to Eq. [18] and increases the saturation of $N_{\text {active }} \rightarrow N_{\text {total }}$ according to Eq. [20]. Furthermore, Eq. [24] implies that the product of $\left(T_{\text {liq }}-T_{\text {amb }}\right)^{3} \rho_{s} c_{p} \lambda_{\text {th }}$ must be lowered to reduce the absorbed power per unit depth $P_{\text {req,in,depth }}$ required for the growth of equiaxed dendritic grains. This may be achieved by adjusting the alloy composition or by choosing a different alloy specified by the DIN EN 573-3 $3^{[23]}$ standard. In conclusion, Eqs. [23] and [24] combine the material and process perspective that ensures the growth of equiaxed dendritic grains.

\section{CONCLUSION}

For the first time the influence of process parameters on the criterion for columnar-to-equiaxed transition in laser beam welding is incorporated in one analytical description. This allows a more nuanced and precise approach to model the columnar-to-equiaxed transition during full penetration laser beam welding of aluminum alloys. The analytical description derived here is somewhat limited in terms of the used nucleation density model, but it can be expanded with a sophisticated model for the distribution of nucleation particles for commercially available aluminum alloys. Future work will focus on the influence of the alloy chemical composition by using more sophisticated nucleation density models.

The analytical description Eq. [23] derived in this study highlights the full range of process and material phenomena in detail. Using that equation the minimum values of 
the welding and material parameters required for the growth of equiaxed dendritic grains can be calculated. Hence, the process and material design can be achieved in advance. The design step can be completed with the help of thermodynamic databases, the fundamentals of laser material processing and the equations provided in this study. The advantage of this method is to control the mechanical properties of the weld seam.

The experiments conducted in this study confirm the analytical description for the special case of full penetration laser beam welding and the validity of the known model by Hunt. Using a high power per unit depth and a high welding velocity is recommended as a practical guideline to achieve the desired equiaxed solidification in full penetration laser beam welding in order to promote its benefits on weld seam strength and hot cracking resistance. This is beneficial for industrial applications because it eliminates the usage of additional grain-refining filler wire for achieving equiaxed solidification in the weld seam and exploits the existing nucleation particles in the alloy. Moreover, the criterion can be adapted for comparable processes like laser-based additive manufacturing, which has to be proven in future work.

\section{ACKNOWLEDGMENT}

This work was funded in parts by the Deutsche Forschungsgemeinschaft (DFG, German Research Foundation) - 398552773.

\section{FUNDING}

Open Access funding enabled and organized by Projekt DEAL.

Open Access This article is licensed under a Creative Commons Attribution 4.0 International License, which permits use, sharing, adaptation, distribution and reproduction in any medium or format, as long as you give appropriate credit to the original author(s) and the source, provide a link to the Creative Commons licence, and indicate if changes were made. The images or other third party material in this article are included in the article's Creative Commons licence, unless indicated otherwise in a credit line to the material. If material is not included in the article's Creative Commons licence and your intended use is not permitted by statutory regulation or exceeds the permitted use, you will need to obtain permission directly from the copyright holder. To view a copy of this licence, visit http://creativecommons. org/licenses/by/4.0/.

\section{REFERENCES}

1. P. Schempp and M. Rethmeier: Weld. World, 2015, vol. 59, pp. $767-84$.

2. C. Hagenlocher, D. Weller, R. Weber, and T. Graf: Sci. Technol. Weld. Join., 2019, vol. 24, pp. 313-19.

3. M. Braccini, C. Martin, and M. Suery: Modeling of Casting, Welding and Advanced Solidification Processes IX, 2000, pp. 18-24.
4. L.J. Barker: Trans. ASM, 1950, vol. 42, p. 347.

5. T. Sun, P. Franciosa, M. Sokolov, and D. Ceglarek: Procedia CIRP, 2020, vol. 94, pp. 565-70.

6. I. Maxwell and A. Hellawell: Acta Metall., 1975, vol. 23, pp. 229-37.

7. M. Johnsson, L. Backerud, and G.K. Sigworth: Metall. Mat. Trans. A, 1993, vol. 24, pp. 481-91.

8. D.H. StJohn, M. Qian, M.A. Easton, and P. Cao: Acta Mater., 2011, vol. 59, pp. 4907-21.

9. A.L. Greer: J. Chem. Phys., 2016, vol. 145, art. no. 211913.

10. E. Liotti, C. Arteta, A. Zisserman, A. Lui, V. Lempitsky, and P.S. Grant: Sci. Adv., 2018, vol. 4, p. 4004.

11. Y. Wang, Z. Que, T. Hashimoto, X. Zhou, and Z. Fan: Metall. Mater. Trans. A, 2020, vol. 51, pp. 5743-57.

12. Z. Fan, F. Gao, B. Jiang, and Z. Que: Sci. Rep., 2020, vol. 10, p. 9448.

13. W. Kurz, C. Bezençon, and M. Gäumann: Sci. Technol. Adv. Mater., 2001, vol. 2, pp. 185-91.

14. M. Gäumann, C. Bezençon, P. Canalis, and W. Kurz: Acta Mater., 2001, vol. 49, pp. 1051-62.

15. Z. Tang and F. Vollertsen: Weld. World, 2014, vol. 58, pp. 355-66.

16. D. Zhang, A. Prasad, M.J. Bermingham, C.J. Todaro, M.J. Benoit, M.N. Patel, D. Qiu, D.H. StJohn, M. Qian, and M.A. Easton: Metall. Mater. Trans. A, 2020, vol. 51, pp. 4341-59.

17. J.H. Martin, B.D. Yahata, J.M. Hundley, J.A. Mayer, T.A. Schaedler, and T.M. Pollock: Nature, 2017, vol. 549, pp. 365-69.

18. C. Hagenlocher: Die Kornstruktur und der Heißrisswiderstand von Laserstrahlschweißnähten in Aluminiumlegierungen, München: utzverlag, 2020.

19. P. Schempp, C.E. Cross, A. Pittner, G. Oder, R.S. Neumann, H. Rooch, I. Dörfel, W. Österle, and M. Rethmeier: Weld. J., 2014, vol. 93, pp. 53-59.

20. C. Hagenlocher, F. Fetzer, D. Weller, R. Weber, and T. Graf: Mater. Des., 2019, vol. 174, art. no. 107791.

21. J.D. Hunt: Mater. Sci. Eng., 1984, vol. 65, pp. 75-83.

22. P. Schempp, C.E. Cross, A. Pittner, and M. Rethmeier: Metall. Mat. Trans. A, 2013, vol. 44, pp. 3198-210.

23. DIN EN 573-3:2013-12: Aluminium and aluminium alloys Chemical Composition and form of wrought products - Part 3: Chemical composition and form of products; German version EN 573-3:2013

24. DIN EN ISO 643: Stahl-Mikrophotographische Bestimmung der erkennbaren Korngröße.

25. J. O. Andersson, T. Helander, L. Höglund, P. Shi, and B. Sundman: Calphad: Computer Coupling of Phase Diagrams and Thermochemistry, 2002, vol. 26, pp. 273-312.

26. J.A. Dantzig and M. Rappaz: Solidification, 2nd ed., EPFL Press, Lausanne, 2016

27. C. Kammerer: Aluminium-Taschenbuch: Band 1: Grundlagen und Werkstoffe, 15th ed., Aluminium-Verlag, Düsseldorf, 1995.

28. W. Kurz and D.J. Fisher: Fundamentals of Solidification, Trans Tech Publications, 1998, vol. 66

29. M.H. Burden and J.D. Hunt: J. Cryst. Growth, 1974, vol. 22, pp. $109-16$.

30. Y.J. Liang, X. Cheng, and H.M. Wang: Acta Mater., 2016, vol. 118, pp. 17-27.

31. A. Kozlov and R. Schmid-Fetzer: IOP Conf. Ser.: Mater. Sci. Eng., 2012, vol. 27, p. 12001.

32. Y. Du, Y.A. Chang, B. Huang, W. Gong, Z. Jin, H. Xu, Z. Yuan, Y. Liu, Y. He, and F.Y. Xie: Mater. Sci. Eng. A, 2003, vol. 363, pp. $140-51$.

33. E. Fraś, K. Wiencek, M. Górny, H.F. López, and E. Olejnik: Metall. Mat. Trans. A, 2013, vol. 44, pp. 5788-95.

34. S. Kou: Welding metallurgy, 2nd ed., Wiley-Interscience, Hoboken N.J., 2003.

35. D. Rosenthal: Weld. J., 1941, vol. 20, pp. 220-34.

36. A. Gouffé: Rev. Opt., 1945, vol. 24, pp. 1-7.

37. H. Hügel and T. Graf: Laser in der Fertigung, 3rd ed., Vieweg + Teubner, Wiesbaden, 2014.

38. S. Geng, P. Jiang, X. Shao, L. Guo, G. Mi, H. Wu, C. Wang, C. Han, and S. Gao: Appl. Phys. A, 2019, vol. 125, pp. 1-7.

Publisher's Note Springer Nature remains neutral with regard to jurisdictional claims in published maps and institutional affiliations. 